\title{
ANALYSIS OF EFFICACY, RECURRENCE AND COMPLICATIONS FOLLOWING PTERYGIUM SURGERY WITH LIMBAL AUTO-CONJUNCTIVAL GRAFT IN FARMERS
}

\author{
Venkatesan Modi Jayaraman', Xavier Jayaseelan², Panimalar Veeramani ${ }^{3}$ \\ ${ }^{1}$ Associate Professor, Department of Ophthalmology, Melmaruvathur Adiparasakthi Institute of Medical Sciences, Kanchipuram, \\ Affiliated to The Tamilnadu Dr. MGR Medical University. \\ ${ }^{2}$ Assistant Professor, Department of Ophthalmology, Saveetha Medical College, Deemed University, Chennai, Tamilnadu. \\ ${ }^{3}$ Assistant Professor, Department of Ophthalmology, Saveetha Medical College, Deemed University, Chennai, Tamilnadu.
}

\begin{abstract}
BACKGROUND

Pterygium is a conjunctival disease, an abnormal triangle fold of membrane secondary to elastotic degenerative condition of the subconjunctival tissue proliferates as vascularised tissue encroaches upon the cornea destroying the superficial layers of the stroma and Bowman's membrane. Recently, it has become clear that ultraviolet light exposure is the most important environmental influence. Surgical excision is the principal mode of therapy for Pterygium. But the high incidence of recurrence following excision remains a challenge unmet and a problem unsolved.

The aim of this study is to evaluate the efficacy of limbal conjunctival autografting in the surgical management of Pterygium in farmers and to analyse the recurrence rates and complications of conjunctival autografting in farmers.
\end{abstract}

\section{MATERIALS AND METHODS}

Prospective observational study of 50 cases of Pterygium. The patients were randomly selected. After pre-operative assessment, patients were taken up for the surgical procedure by a single surgeon. All the patients followed up post-operatively for 1 year. A recurrence was defined as a fibrovascular tissue crossing the corneo-scleral limbus on to clear cornea in the area of previous Pterygium excision.

\section{RESULTS}

In this study, $60 \%$ of patients were in the age group of 21 to 40 years. The commonest indication for surgery was cosmetic disfigurement $56 \%$ followed by ocular irritation and recurrent inflammation. The recurrence rate is $16.00 \%$ in the study. The complications in conjunctival autograft were granuloma at donor site, graft displacement, graft retraction and suture irritation.

\section{CONCLUSION}

Limbal conjunctival autograft is a safe, effective and affordable procedure in the management of Pterygium in farmers those who are at the risk of UV exposure. The recurrence rate could be reduced by health education, lifestyle modification and precautions. Complications can be avoided by simple precautions and refinement in surgical technique.

\section{KEYWORDS}

Pterygium, Limbal Autograft, Recurrence Rate, Precautions, Minimal Complications, No Special Instrumentation.

HOW TO CITE THIS ARTICLE: Jayaraman VM, Jayaseelan X, Veeramani P. Analysis of efficacy, recurrence and complications following pterygium surgery with limbal auto-conjunctival graft in farmers. J. Evolution Med. Dent. Sci. 2017;6(32):2600-2604, DOI: $10.14260 /$ Jemds/2017/562

\section{BACKGROUND \\ Pterygium is a conjunctival disease, an abnormal triangle fold of membrane secondary to elastotic degenerative condition of the subconjunctival tissue proliferates as vascularised tissue encroaches upon the cornea destroying the superficial layers of the stroma and Bowman's membrane. Recently, it has become clear that ultraviolet light ${ }^{[1]}$ exposure is the most important environmental influence. Surgical excision is the principal mode of therapy for Pterygium. But the high incidence of recurrence following excision remains a}

Financial or Other, Competing Interest: None.

Submission 27-02-2017, Peer Review 07-04-2017,

Acceptance 13-04-2017, Published 20-04-2017.

Corresponding Author:

Dr. Venkatesan Modi Jayaraman,

Associate Professor,

Department of Ophthalmology,

Melmaruvathur Adiparasakthi Institute

of Medical Sciences, Melmaruvathur,

Kanchipuram-603319.

E-mail: drvenkatesan.mj@gmail.com

DOI: $10.14260 /$ jemds $/ 2017 / 562$ challenge unmet and a problem unsolved. The evolution of various surgical techniques and various adjuncts[2] to surgical excision has been on the sole aim of preventing recurrence. The various procedures used in the management of Pterygium may be evaluated based on two principal criteria namely, safety (Freedom from sight threatening complications) and efficacy (Freedom from recurrence).

The various adjunctive treatments include topical corticosteroids, beta irradiation, argon and excimer laser, thiotepa, mitomycin $C$, etc. Post-operative $\beta$ radiation[3] is associated with variable recurrence rates $(0.5 \%$ to $33 \%)$ as well as serious complications like infections, sclera ulceration and cataract formation. Post-operative thiotepa causes depigmentation of lids in darkly pigmented patients. There have been several reports in the literature supporting the efficacy of post-operative mitomycin $\mathrm{C}^{[4]}$ in preventing Pterygium recurrence. However, serious vision threatening complications have been reported with Mitomycin $\mathrm{C}$ such as sclera thinning, ulceration and perforation, etc. Bare sclera excision is still practiced widely around the world as a basic and simple technique for Pterygium removal. Conjunctival 
autograft is widely accepted as a safe and effective surgical modality in the treatment of Pterygium, but recurrence rates still vary considerably in literature. The concept on the aetiopathogenesis of Pterygium is that it is a consequence of localised damage to the limbal stem cells brought about by exposure to ultraviolet light. The surgical procedure of limbal conjunctival autograft while removing the damaged cells replenishes the area with healthy limbal stem cells[5] from the superotemporal conjunctiva, which is less exposed to actinic damage. Therefore, recurrence may be reduced.

Melmaruvathur is a gram panchayat situated in Cheyyur sub-district, Kanchipuram district, Tamilnadu, India with total geographical area of 149.61 hectares. Surrounded by 12 villages were agriculture and farming is the main work of the people living here. This study was undertaken to analyse the efficacy of limbal conjunctival autograft and recurrence rate in farmers who are the outdoor workers exposed to hot, dry, dusty conditions and have a predilection for developing Pterygium and recurrence.

\section{MATERIALS AND METHODS}

This is a prospective observational study of fifty cases of Pterygium who presented to the outpatient in Department of Ophthalmology in Melmaruvathur Adiparasakthi Institute of Medical Sciences from October 2014 to March 2016. All patients provided informed, written consent. The patients were randomly selected irrespective of their age and sex.

\section{Inclusion Criteria}

Only primary Pterygium was chosen for the study. The Pterygium had to be $2 \mathrm{~mm}$ or more in size and progressive, as evidenced by fleshiness and vascularity, were included in the study. Farmer or agriculture related work by occupation.

\section{Exclusion Criteria}

Atrophic Pterygium and Pterygium less than $2 \mathrm{~mm}$ in size. Eyes which showed evidence of any ocular surface disorder (e.g. Dry eye) or any other disorder of the ocular adnexa. Patient with history of any chemical injury. Patient with bleeding disorders or systemic disease that could affect the wound healing postoperatively.

Pre-operatively uncorrected and corrected visual acuity were recorded in all the cases. A baseline IOP measurement was done in all the cases using Goldmann Applanation tonometer. A slit lamp examination was performed and a careful assessment of the morphology, vascularity and size of the Pterygium was made along with a routine examination of the ocular adnexa and the anterior segment. The size of the Pterygium was recorded as millimetres of encroachment from the limbus. After assessment, patients were subjected to the surgical procedure.

\section{Limbal Conjunctival Autografting Technique}

The conjunctiva was anaesthetised by topical instillation of $4 \%$ xylocaine eye drops. The conjunctiva overlying the Pterygium was elevated by injecting $0.5 \mathrm{~mL}$ of $2 \%$ xylocaine subconjunctivally. The head of the Pterygium was grasped with a fixation forceps. Starting 0.5 to $1 \mathrm{~mm}$ in front of its apex the Pterygium was shaven off from the cornea with a crescent blade, the dissection being carried up to the limbus. With the aid of a spring action scissors, the Pterygium was freed from the overlying conjunctiva and the underlying sclera by blunt dissection. Care was taken not to injure the medial rectus muscle. The Pterygium was excised along with a part of the conjunctiva and the underlying tenon's capsule, leaving behind an area of bare sclera at the limbus. A stay suture was applied at the 12 o'clock limbus to aid in rotating the globe. Haemostasis of the exposed sclera surface was obtained using wet field cautery. The size of conjunctival graft required to resurface the exposed sclera surface was determined using a Castroviejo calipers. The measured dimensions were marked onto the superotemporal conjunctiva with several cautery spots. Care was taken to obtain as thin a graft as possible without buttonholing. A limbus orientation was maintained. The graft was smoothened out in its bed taking care to avoid any folding of the edges. The position of the graft was secured using interrupted 10-0 nylon sutures. The four corners of the graft were anchored with episcleral bites to maintain position. No sutures were placed on the limbal side of the graft. The eye was firmly patched with an antibiotic eye ointment. Postoperatively, topical dexamethasone eye drops were used every $2 \mathrm{hrs}$. for the first post-operative week and then tapered over the next $5-6$ weeks. Antibiotic eye ointment was used 3 times daily. After the immediate post-operative period patients were seen at 6 weeks, 3 months, 6 months and 1 year. During each followup visit, the patient was subjected to slit lamp examination and the visual acuity and intraocular pressure were recorded. A recurrence was defined as fibrovascular tissue crossing the cornea sclera limbus onto the clear cornea in the area of previous Pterygium excision.

The collected data was statistically analysed. To describe about the data descriptive statistics, percentage analysis were used.

The study was reviewed by the appropriate Ethics Committee and has been performed in accordance with the ethical standards of the most recent version of the 1964 Declaration of Helsinki.

\section{RESULTS}

Out of the fifty patients analysed, $42 \%$ were in the age group of 31 to 40 years and $18 \%$ were in the age group of 21 to 30 years. Both put together, $60 \%$ of the patients were in the age group of 21 to 40 years. $59 \%$ of the patients were men and $41 \%$ were women. The Pterygium was present on the right eye in $45 \%$ of the patients and on the left eye in $41 \%$ of the patients, $14 \%$ had bilateral Pterygium. $96 \%$ of the Pterygium was present on the nasal side. The predominantly nasal location of Pterygium has been attributed to greater exposure of the nasal interpalpebral conjunctiva to ultraviolet radiation. 3\% of the patients had both nasal and temporal Pterygium (Biheaded). Presence of biheaded[6] Pterygium might indicate a more widespread actinic damage of the limbal stem cells.

\section{Follow-Up}

The average followup period was 6 months to 1 year. $96 \%$ of the patients were followed up for 1 year. Two patients lost to follow up after six months.

The commonest indication for surgery in this study group was cosmetic disfigurement (56\%) and ocular irritation (28\%). Other indications were recurrent inflammation (10\%) and visual impairment (6\%). The total number of recurrences was eight and the recurrence rates ${ }^{[7]}$ is $16.00 \%$. 


\begin{tabular}{|c|c|c|}
\hline Time & No. of Recurrences & Percentage \\
\hline 0 - 6 Weeks & - & - \\
\hline 6 Weeks to 3 Months & 1 & 12.50 \\
\hline 3 to 6 Months & 3 & 37.50 \\
\hline 6 Months to1 Year & 4 & 50.00 \\
\hline \multicolumn{2}{|c|}{ Table 1. Time of Recurrence } \\
\hline
\end{tabular}

Around $12.50 \%$ of all the recurrences occurred between six weeks and three months after surgery. $37.50 \%$ of the recurrences ${ }^{[8]}$ occurred between 3 to 6 months. $50 \%$ of the recurrence occurred between 6 months to 1 year. No recurrences were found before 6 weeks.

\begin{tabular}{|c|c|c|}
\hline Age Groups & No. of Recurrences & Percentage \\
\hline $0-20$ & 0 & 0 \\
\hline $21-30$ & 1 & 12.50 \\
\hline $31-40$ & 4 & 50.00 \\
\hline$>40$ & 3 & 37.50 \\
\hline Total & $\mathbf{8}$ & $\mathbf{1 0 0}$ \\
\hline \multicolumn{3}{|c|}{ Table 2. Age and Recurrence } \\
\hline
\end{tabular}

In this study, most of the recurrences were found below 40 years' age group. $12.50 \%$ occurred in the 21 to 30 years' age group and $50.00 \%$ occurred in the 31 to 40 years' age group. Around $37.50 \%$ recurrence is witnessed in $>40$ age group and the significance of these findings need further statistical analysis.

\begin{tabular}{|c|c|c|c|}
\hline $\begin{array}{c}\text { Sl. } \\
\text { No. }\end{array}$ & Complication & $\begin{array}{c}\text { No. of } \\
\text { Patients }\end{array}$ & Management \\
\hline 1 & $\begin{array}{c}\text { Granuloma } \\
\text { at the } \\
\text { Donor Site }\end{array}$ & 1 & $\begin{array}{c}\text { Excision of Granuloma } \\
\text { Raw Area Covered with } \\
\text { Adjacent Conjunctiva }\end{array}$ \\
\hline 2 & Graft Rejection & 1 & $\begin{array}{c}\text { Re-Grafting with } \\
\text { Conjunctival Flap from } \\
\text { Fellow Eye }\end{array}$ \\
\hline 3 & Suture Irritation & 4 & Suture Removal \\
\hline 4 & Graft Retraction & 2 & Re-grafting \\
\hline 5 & Elevation of IOP & 3 & Steroid Withdrawn \\
\hline \multicolumn{3}{|r|}{ Table 3. Complications } \\
\hline
\end{tabular}

Suture irritation at the graft site was the commonest complication followed by elevation of IOP. Totally three patients showed an increase in IOP, which returned to normal following withdrawal of steroids. The other complications were granuloma at the donor site, graft rejection and graft retraction.

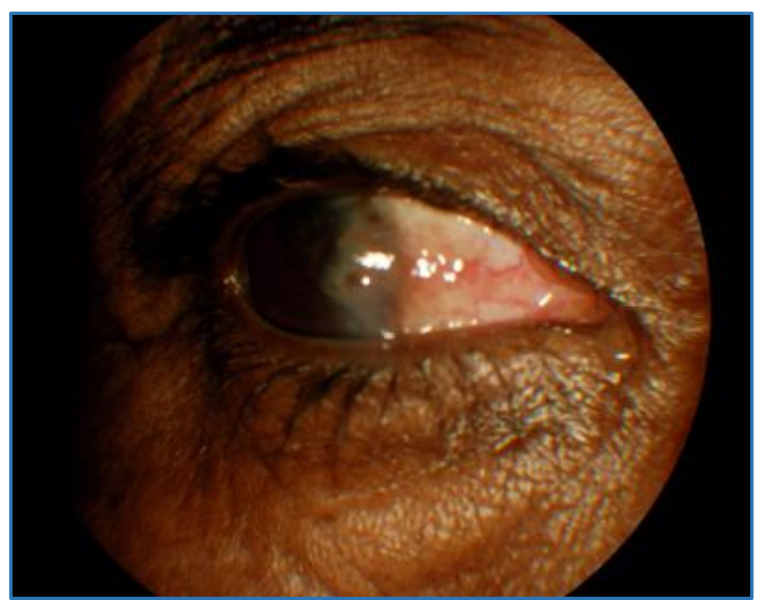

Figure 1. Pre-Operative PhotographProgressive Nasal Pterygium

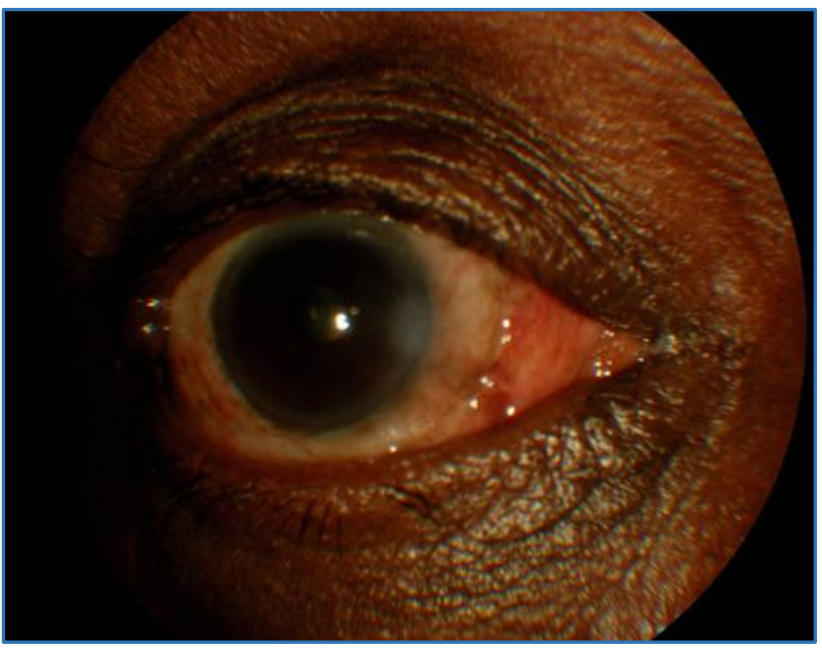

Figure 2. Post-Operative PhotographLimbal Autoconjunctival Graft

\section{DISCUSSION}

In this study of 50 patients with Pterygium, $60 \%$ were in the age group of 21 to 40 years. This age distribution correlates with the reports in the literature stating the age groups for maximum incidence of Pterygium to be between 20 and 40 years. $59 \%$ of the patients in this study group were men. Though majority of patients in this study group were men, a slight male preponderance in the incidence of Pterygium [9] has been reported in literature as well. This has been attributed to the fact that men are likely to remain outdoors more often than women and have an increased risk of exposure to sunlight,[10] but in our study both the male and female patients were involved, those who indulge in outdoor agriculture field works. $96 \%$ of the patients had nasal Pterygium. The commonest indication for surgery was cosmetic disfigurement (59\%) followed by ocular irritation (25\%) and recurrent inflammation (10\%). The average followup period was 6 months to 1 year, $96 \%$ of the patients were followed up for 1 year. The recurrence rate was $16.00 \%$ following limbal conjunctival autografting.[11] In our study though the recurrence rate is slightly higher when correlated with study of Srinivas et al[12] may be because all our subjects in this study are farmers, those have a more risk of UV exposure.

Most of the recurrences in our study, $50.00 \%$ were found during 6 months to 1 year after surgery. $37.50 \%$ of the recurrences occurred between 3 to 6 months. $12.50 \%$ of the recurrence occurred between 6 weeks to 3 months. No recurrences were found before 6 weeks. It has been reported in the study of Allan et al[13] that the maximum numbers of recurrences following Pterygium excision occur during the first six months after excision, a majority of them occurring on the first 3 months. Most of the patients who developed recurrence ${ }^{14]}$ were in below 40 years' age group. Maximum of $50.00 \%$ in 31 - 40 years' age group followed by 21 - 30 age accounting to $12.50 \%$.

Complications were observed in the study. One patient[15] developed a granuloma at the donor site. The granuloma was excised and the raw area was covered by mobilising the adjacent conjunctiva. Three patients had an elevation of IOP above the baseline, at the end of six weeks. On withdrawal of steroids and during the subsequent visits, the IOP returned to normal. One patient had rejection and sloughing ${ }^{[16]}$ of the 
graft on the second postoperative day. It was found to be due to incorrect placement of the graft with the epithelial surface facing the sclera. This complication[17] can be avoided by marking the epithelial surface of the graft with cautery or gentian violet. The sloughed graft was removed and a regrafting was done using a conjunctival flap[18] from the fellow eye. Two patients showed shrinkage and retraction of the graft post-operatively and eventually had a recurrence. This complication can occur either due to inadequate graft size or due to the inclusion of Tenon's tissue in the graft.[19] Four patients complained of suture irritation. The sutures were removed at the end of six weeks.

\section{CONCLUSION}

In Rural population, especially farmers, those exposed to harmful UV radiation secondary to prolonged outdoor activities. Limbal conjunctival autografting[20] is a safe and effective procedure in the management of Pterygium and it is affordable to the people living in lower social economic status. The advantages of limbal conjunctival autografting over other modalities of treatment are low recurrence rate,[21] fewer and no sight threatening complications when compared to antimetabolites,[22] offers anatomical and physiological restoration of ocular surface.[23] Simple procedure not requiring additional surgical skill or instrumentation and does not require any special postoperative care. Cost effective for poor patients and further we have reduced the cost of the procedure by securing graft 10-0 nylon sutures.

Though the recurrence is common in this study, but still the majority of the subjects had the benefit of no recurrence which is in favour of limbal conjunctival graft. [24] Proper health education to patients about lifestyle modification and few precautions like sun glasses, avoiding outdoor activities, during peak hours, etc. could still reduce the recurrence rate. The post-operative complications are minimal and managed by simple procedures. Most of the complications were related to the surgical technique and can be avoided by taking simple precautions. Incorrect placement of the graft can be avoided by marking the epithelial surface of the graft with cautery or gentian violet. Retraction and shrinkage can be avoided by taking as thin a graft as possible and by taking a graft slightly larger than the bare scleral area.

\section{REFERENCES}

[1] Coroneo MT. Pterygium as an early indicator of ultraviolet insolation: a hypothesis. Br J Ophthalmol 1993;77(11):734-9.

[2] Kaufman SC, Jacobs DS, Lee WB, et al. Options and adjuvants in surgery for pterygium: a report by the American Academy of Ophthalmology. Ophthalmology 2013;120(1):201-8.

[3] MacKenzie FD, Hirst LW, Kynaston B, et al. Recurrence rate and complications after beta irradiation for pterygia. Ophthalmology 1991;98(12):1776-81.

[4] Chen PP, Ariyasu RG, Kaza V, et al. A randomized trial comparing mitomycin $\mathrm{C}$ and conjunctival autograft after excision of primary pterygium. Am J Ophthalmol 1995;120(2):151-60.
[5] Dua HS, Saini JS, Azuara-Blanco A, et al. Limbal stem cell deficiency: concept, aetiology, clinical presentation, diagnosis and management. Indian J Ophthalmol 2000;48(2):83-92.

[6] Karukonda SR, Thompson HW, Beuerman RW, et al. Cell cycle kinetics in pterygium at three latitudes. Br J Ophthalmol 1995;79(4):313-7.

[7] Tan DT, Chee SP, Dear KB, et al. Effect of pterygium morphology on pterygium recurrence in a controlled trial comparing conjunctival autografting with bare sclera excision. Arch Ophthalmol 1997;115(10): 1235-40.

[8] Hirst LW, Sebban A, Chant D. Pterygium recurrence time. Ophthalmology 1994;101(4):755-8.

[9] Oguz H. Inferior limbal conjunctival autograft transplantation for recurrent Pterygium. Indian J Ophthalmol 2003;51(1):108-9.

[10] Schwartz GS, Holland EJ. Latrogenic limbal stem cell deficiency. Cornea 1998;17(1):31-7.

[11] Kenyon KR, Wagoner MD, Hettinger ME. Conjunctival autograft transplantation for advanced and recurrent pterygium. Ophthalmology 1985;92(11):1461-70.

[12] Rao SK, Lekha T, Mukesh BN, et al. Conjunctival-limbal autografts for primary and recurrent pterygia: technique and results. Indian J Ophthalmol 1998;46(4):203-9.

[13] Allan BD, Short P, Crawford GJ, et al. Pterygium excision with conjunctival autografting: an effective and safe technique. Br J Ophthalmol 1993;77(11):698701.

[14] Mutlu FM, Sobaci G, Tatar T, et al. A comparative study of recurrent pterygium surgery: limbal conjunctival autograft transplantation versus mitomycin C with conjunctival flap. Ophthalmology 1999;106(4):817-21.

[15] Kheirkhah A, Hashemi H, Adelpour $M$, et al. Randomized trial of pterygium surgery with mitomycin $\mathrm{C}$ application using conjunctival autograft versus conjunctival-limbal autograft. Ophthalmology 2012;119(2):227-32.

[16] Kheirkhah A, Nazari R, Nikdel M, et al. Postoperative conjunctival inflammation after pterygium surgery with amniotic membrane transplantation versus conjunctival autograft. Am J Ophthalmol 2011;152(5):733-8.

[17] Rubinfeld RS, Pfister RR, Stein RM, et al. Serious complications of topical mitomycin-C after pterygium surgery. Ophthalmology 1992;99(11):1647-54.

[18] Lam DS, Wong AK, Fan DS, et al. Intraoperative mitomycin $\mathrm{C}$ to prevent recurrence of pterygium after excision: a 30-month follow-up study. Ophthalmology 1998;105(5):901-5.

[19] Mahar PS. Conjunctival autograft versus topical mitomycin $\mathrm{C}$ in treatment of pterygium. Eye (Lond) 1997;11(Pt 6):790-2.

[20] Kwon SH, Kim HK. Analysis of recurrence patterns following pterygium surgery with conjunctival autografts. Medicine (Baltimore) 2015;94(4):e518.

[21] Frucht-Pery J, Ilsar M. The use of low-dose mitomycin C for prevention of recurrent pterygium. Ophthalmology 1994;101(4):759-62. 
[22] Cano-Parra J, Diaz-Llopis M, Maldonado MJ, et al. Prospective trial of intraoperative mitomycin $\mathrm{C}$ in the treatment of primary pterygium. Br J Ophthalmol 1995;79(5):439-41.

[23] Chan CC, Holland EJ. Severe limbal stem cell deficiency from contact lens wear: patient clinical features. Am J Ophthalmol 2013;155(3):544-9.e2.
[24] Al Fayez MF. Limbal versus conjunctival autograft transplantation for advanced and recurrent pterygium. Ophthalmology 2002;109(9):1752-5. 